\title{
NIETZSCHE: DE HERÁCLITO AL MUNDO
}

Nietzsche: from Heraclitus to the World

\author{
José Ramón Arana
}

Universidad del País Vasco

\begin{abstract}
Resumen: Se ensaya en este artículo una metodología nueva en el estudio de Nietzsche: poner en conexión la estructura profunda de su pensamiento con sus manifestaciones de superficie en forma de obras. Esta metodología es especialmente indicada en el caso de Nietzsche por la variación constante de su pensamiento. Se aplica a un solo aspecto: su interpretación juvenil de Heráclito y su conceptualización madura del «mundo». No solo el texto de madurez aclara y desarrolla ideas del texto de juventud, sino que el texto de juventud enmarca la posible interpretación de la obra de madurez, sin que ninguno de los dos pierda originalidad: se aclaran mutuamente. poder

Palabras clave: inocencia del devenir - juego del mundo - mundo - voluntad de
\end{abstract}

AbSTRAct: A new method in studying Nietzsche is attempted in this article: connecting the deep structure of his thinking with his external manifestations in the form of works. This methodology is specially indicated in Nietzsche due to the continuous variations in his thinking. It is applied to only one aspect: his junior interpretation of Heraclitus in comparison with his mature conceptualization of «world». While his maturity texts clarify and develop ideas of his youth works, these last ones frame the possible interpretation of his maturity works, without loosing originality neither of them: they explain each other.

Keywords: Innocence of becoming - World play - World - Will to power

Hay escritores que, una vez que se han encontrado a sí mismos, solo escriben ya especificaciones y desarrollos de algunos puntos de su filosofía que estaban quizás implícitos en su obra máxima o que merecían una precisión más detallada. Otros se reiteran, si son imaginativos, con variaciones estilísticas creativas, pero, si no lo son, se repiten hasta el punto de parecer carentes de ideas y cosificados en sus formas expresivas.

Nietzsche no pertenece a ninguno de estos grupos. No quiero negar, en modo alguno, que no tenga obras que no sean especificaciones, por ejemplo, Más allá del bien y del mal y La genealogía de la moral, o que Nietzsche no reitere: es constante en sus obsesiones, pero su capacidad de variación es tal que genera en el lector no la desgana, sino el deseo de esas mil formas nuevas de decir esas mismas obsesiones y el ansia de la sorpresa de esas mil maneras distintas. Nietzsche no solo es un escritor de principios, sino también de ideas; por eso también suele confundir a escritores escolásticos. 
Quienes estudian a Nietzsche suelen resumir y clasificar estas variaciones y clasificaciones en fases: la fase filológica, la positivista...; en este método la determinación de las diferencias es fundamental; y no solo aducen el apoyo de los textos, sino alguna declaración del propio Nietzsche:

A los lectores de mis primeros escritos quiero explicarles explícitamente que he superado las opiniones artísticometafísicas que los dominan esencialmente: son agradables, pero insostenibles. Quien se permite hablar públicamente de manera prematura, se ve obligado a menudo a contradecirse públicamente de esas opiniones ${ }^{1}$.

Yo, en cambio, ensayaré otro procedimiento: intentaré explicar algunas ideas de Nietzsche a partir de la conceptualización obra producida / estructura profunda. Luego veremos la rentabilidad intelectual que se obtiene con este método para su comprensión. Nietzsche tiene a partir de cierto momento, antes por supuesto de 1877, unas inquietudes básicas que no le desaparecerán jamás: la concepción moral frente a la concepción estética del mundo, la vitalidad desde sí mismo frente al resentimiento, el juego frente la lógica, el carácter modélico de los griegos, la anulación de las dualidades y pocas más. Todas ellas las llevó a explicitación, porque Nietzsche fue un escritor lúcido no solo frente a los problemas de su tiempo y de la cultura europea, y a los problemas del entendimiento y de la vida, sino también frente a sus propias concepciones. También es verdad que alguno de ellos adquirió relevancia hasta focalizar el núcleo de obras enteras. Pero a ninguna renunció jamás, ni se olvidó de alguna como para que dejaran de influir de una manera u otra en los temas sobre los que estaba escribiendo en un momento dado.

Estos problemas son lo que podemos llamar la estructura profunda del pensamiento de Nietzsche. Cuando uno escribe un artículo, un libro o da una conferencia, esta estructura debe plasmarse en una obra de superficie y adquirir así una forma: «superficie» aquí, por supuesto, no tiene un valor peyorativo ni es un juicio de valor. Este nivel de superficie es el del lector: nosotros leemos a este nivel y, todo lo más, nos vemos obligados o arrojados a buscar esa estructura profunda; es el proceso inverso al del escritor ${ }^{2}$. Como se trata de una estructura y esta estructura en Nietzsche es compleja, esta temática permite diversas combinaciones posibles y diversas proyecciones al nuevo nivel. Dejo de lado aquello en que muchos se han fijado ya en Nietzsche: su dominio absoluto de dos modos estilísticos de expresarse: el aforismo y el discurso seguido ${ }^{3}$. Yo pienso en otras formas de proyección de esas estructuras profundas en superficie.

En Nietzsche hay varios retablos conseguidos, todos de manera magistral. El nacimiento de la tragedia es uno, obra en forma de puente, en que el carácter modélico de los griegos se combina con la anulación del tiempo (en otro

1. Cf. KSA VIII 463.

2. Desde aquí se puede entender el método interpretativo que Heidegger aplicó a la lectura del pensamiento occidental y que llamó un Schritt zurück, un "paso atrás», cf. Grundfragen der Philosophie. Ausgewählte Probleme der Logik (1937-1938), ed. de F. W. von Hermann, en Gesamtausgabe, II, B, vol. 45, Frankfurt a. M.: V. Klostermann, 1984, pp. 144-145; e Identität und Differenz, Tübingen, 1957, pp. 39 ss; cf. J. R. Arana, Hermenéutica contemporánea occidental, San Sebastián: Universidad del País Vasco, 2007, pp. 208-210.

3. Cf. A. Nehamas, Nietzsche: Life as Literature, Cambridge MA: Harvard UP, 1995. 
momento lo llamará «nihilismo negativo») para construir un mundo glorioso («nihilismo positivo») y generar una obra admonitoria. Otra proyección de superficie, sin duda la obra más lograda de Nietzsche, Así habló Zaratustra, plasma el tema de vivir desde sí con una riqueza y variedad que no deja nada que desear, mitologizando ese interés en una figura que es tanto símbolo como historia; el himno es aquí el instrumento para pasar de la estructura profunda a la superficie; el resultado es esta obra cumbre de la literatura europea.

Lo mismo se puede decir de su otra obra de juventud que dejó manuscrita, La filosofía en la época trágica de los griegos (1876). El mecanismo de proyección es el relato histórico y la técnica consiste en encontrar en cada presocrático un punto central de la propia filosofía de Nietzsche; al exponer al presocrático respectivo, Nietzsche hará consciente el problema y, al contraponer unos con otros, mostrará las variantes de ese problema, al tiempo que, al criticarlos, irá haciéndose sitio junto a ellos: el infinito, el caos, el devenir, los contrarios, el mundo, la actitud del hombre ante la vida y el mundo son los temas de este pequeño libro magistral. El que haya quedado inacabado no le quita ningún valor: solo nos queda a nosotros la nostalgia de su acabamiento. Pero, como en los torsos escultóricos o en los esbozos arquitectónicos, hay una belleza en lo inacabado. En esta obra Nietzsche logra exponer su admiración por los presocráticos y decirnos, con mayor precisión que lo había hecho en El nacimiento de la tragedia, en qué se apoya esa admiración. Y, al hacerlo, se aglutinan los diversos temas de su estructura profunda en esta obra de superficie: esta obra se convierte en un catalizador en forma de relato histórico.

Esta afirmación se podría demostrar paso a paso, analizando la interpretación de cada presocrático y comprobando cómo persiste esta temática a lo largo de su vida. Pero esta tarea excedería las posibilidades de un artículo. Yo me voy a ceñir a algo mucho más reducido: su interpretación de Heráclito. Este estudio mío, insisto, no estará guiado por ningún afán de filólogo positivista (fuentes y fidelidad de Nietzsche a los textos.... $)^{4}$, sino por el doble propósito de mostrar en un punto esta correlación entre estructura profunda y superficie, y por alumbrar algunas perspectivas del uso de este método.

\section{INTERPRETACIÓN NIETZSCHEANA DE HERÁCLITO}

Heráclito sería el pensador de la «inocencia del devenir». Heráclito piensa la justificación del devenir: el devenir no es una desgracia que exigiese un lamento ni siquiera un hecho que debe ser explicado; lo primero supondría condenar lo temporal por caduco; lo segundo, sería una intromisión, incluso preponderancia, del pensamiento científico en una realidad filosófica. En su lectura de Heráclito, por tanto, Nietzsche se propondrá una interpretación filosófica valorativa del devenir. Eso se resume en la idea de que Heráclito justifica el devenir.

4. Sobre las fuentes que utilizó Nietzsche y la bibliografía secundaria que usó en su interpretación de Heráclito, cf. K. Löwith, Nietzsches Philosophie der ewigen Wiederkehr des Gleichen, Berlin: Verlag Die Runde, 1935, pp. 120 ss; J. B. Hershbell y S. A. Nimis, "Nietszche and Heraclitus»: Nietzsche-Studien 8 (1979), 17-38; y J. J. Colomina Alminyana, «Nietzsche y Heráclito»: Éndoxa 23 (2009), 177-190. 
Para ello Nietzsche debe leer unitariamente los fragmentos llamados «físicos» de Heráclito, que consideran al fuego como el elemento primordial, y los fragmentos filosóficos, que hablan de unidad y pluralidad. Esta compenetración de ambas dimensiones no es fácil, pues la transmisión, ya desde la Antigüedad, se ha empeñado en separarlos. Y esta tendencia se ha reforzado en el mundo moderno con la separación estricta entre ciencia y filosofía. Si Nietzsche logra esta lectura unitaria, será a través y contra no de interpretaciones concretas, sino de nubes de categorizaciones que se interponen entre Heráclito y nosotros, rompiéndolas.

Durante todo este libro el lenguaje que utiliza Nietzsche es cosmológico, pues es el lenguaje que utilizaron aquellos filósofos: frente a los historiadores posteriores, como Aristóteles, que introducen categorizaciones más metafísicas (uno - múltiple), Nietzsche se atiene al lenguaje y al planteamiento de Heráclito.

El primer paso de esta interpretación consiste en afirmar que la realidad es acción: frente a la concepción inercial moderna del cosmos, en que solo hay choques, el universo de Heráclito sería una actividad permanente, sin reposo, un vaivén gigantesco. Este vaivén no consistiría en que unas cosas choquen contra otras, sino en que cada cosa lucha consigo misma, porque encierra en sí su propia contradicción. Los contrarios no son elementos diversos, sino dimensiones diversas de una misma realidad, tanto a nivel de cada una de las cosas como a nivel del conjunto de las cosas. Nietzsche asume en esta interpretación ese eco obsesivo del pánta presocrático, que los traductores actuales se empeñan en traducir por «todo», pero que se queda muy corto, puesto que el plural griego designa una totalidad distributiva («cada una de las cosas que hay»), y una totalidad sumativa («el conjunto de lo que hay»). Nietzsche es plenamente consciente de esta doble dimensión presente en los presocráticos desde la primera vez que la formuló Tales («el agua es el principio de todas las cosas»), y encaja la teoría de los contrarios en esta noción de totalidad, formando entre los dos tipos de totalidad una realidad dinámica. Los contrarios no son las partes de un conjunto, sino los dinamizadores y promotores de ese movimiento. La contradicción está presente en la realidad no como una deficiencia, sino haciéndola ser como es, dinámica, acción. Y frente a Hegel, que esperaba y exigía una conciliación de los contrarios, Heráclito no hablaría para nada de superación alguna.

Y, como observa Nietzsche, este descubrimiento, debería ser sobrecogedor: porque todo el universo en que se vive, el cosmológico, el social, el político, el moral, se viene abajo, la tierra se mueve bajo nuestros pies. Esta experiencia que en otros provocaría terror, en Heráclito se convierte en asombro feliz, en gozo feliz.

Esta contradictoriedad intrínseca no es la señal de que el mundo está mal hecho o de que aún le falta algo por hacer o de que aún debe recorrer un camino hasta que los elementos se aquieten y las contradicciones desaparezcan. Es la ley misma del universo, su necesidad, la contradicción y la necesidad son lo mismo, el universo está regido por una ley insuperable, la contradicción; como han dicho desde siempre los filósofos, al menos desde Platón, el universo no es el reino de la arbitrariedad, sino el de la necesidad; pero, sorprendentemente, a diferencia de todos los filósofos, en Heráclito esa necesidad no excluye la contradicción, sino que se identifica con ella: el universo es necesaria e intrínsecamente contradictorio. La contradicción es la ley universal: es la «justicia eterna». Frente a Anaximandro que, según la interpretación de Nietzsche, considera estos nacimientos y muertes, estas apariciones y desapariciones, como la injusticia del 
universo y que por eso deben pagar las cosas, para Heráclito esa, y no otra, sería la justificación de su existencia. La contradicción no excluye, sino crea.

Pero ¿̇ómo compaginar este movimiento de contrarios? ¿Cómo es posible que los contrarios no solo convivan, sino que no excluyan y que además creen un universo feliz? Nietzsche no puede recurrir a una explicación «racional», puesto que para él la razón es el ámbito de la regulación conceptual y ya se sabe que los conceptos se rigen por el principio de no contradicción. Y es en este punto donde Nietzsche da el salto más sorprendente y lanza otra categoría definitiva: esta oposición de contrarios, que a primera vista parece como una lucha, resulta ser «el mundo como el juego de Zeus». La ley unificadora del universo es el juego.

En el juego de la actividad incesante el jugador se recrea en el trabajo, sin medir sus obras ni por el tiempo ni por el esfuerzo, solo por el placer de recrearse y de plasmarse. El jugador y el artista son una y la misma cosa, lo mismo que el niño. El universo es un niño que juega como un artista: hace y deshace lo que él mismo ha producido. No cualquier producto es artístico y toda obra de arte se somete a reglas sumamente rigurosas. Ninguna obra es necesaria, solo es necesario al artista y al niño el jugar y el producir. Y con el mismo goce con que el niño crea sus castillos de arena en la playa y el artista pinta sus cuadros o esboza sus improvisaciones musicales, con el mismo los destrozan, los borran o los olvidan. El universo nace y muere, teje y desteje, se transforma. Y esta transformación destructora - creadora es su felicidad y su necesidad.

Como este devenir es la justicia, como en él el universo se re-crea, como en él se actúa con la inconsciencia del niño feliz, Nietzsche ha resumido esta concepción heraclítea del universo en una de sus expresiones más logradas: «la inocencia del devenir» ${ }^{5}$. Resumiendo, Heráclito es el pensador de la inocencia del devenir.

\section{CONCEPTO NIETZSCHEANO DE MUNDO}

Nietzsche contrapuso desde muy temprano la justificación moral del mundo a su justificación estética. La primera la rechaza de plano, fue su enemiga declarada y, aunque emplea palabras suaves en su crítica, ve en ella la concepción de Anaximandro, que piensa, según Nietzsche, que la existencia de las cosas es una injusticia y que, por eso, deben pagar un castigo. La justificación estética se resume en la felicidad del juego y en la creatividad, en la asunción gozosa de lo que hay, del devenir: es el modelo de Heráclito. Incesantemente escribirá Nietzsche a lo largo de su vida sobre estas dos concepciones y en sus manuscritos es un tema recurrente ${ }^{6}$.

5. Para la interpretación de Heráclito, cf. PHG caps. 5-8, en KSA I 822-835.

6. Sobre la justificación moral del mundo, cf. P. Kouba, El mundo según Nietzsche. Interpretación filosófica, trad. de J. A. Sánchez, Barcelona: Herder, 2009, pp. 154-169 (sistemático, no cronológico). Sobre la justificación estética del mundo, nada mejor que el siguiente texto de Nietzsche, que resume su biografía intelectual: «Siempre me he preocupado por demostrar la inocencia del devenir: [...] para perseguir fines que se relacionan con el futuro de la humanidad. La primera solución la encontré en la justificación estética de lo que hay. [...]. La segunda solución la encontré en la ausencia de valor de todos los conceptos de culpa y en la comprensión del carácter subjetivo, necesariamente injusto e ilógico, de toda vida. La tercera solución la encontré en la negación de todos los fines y en la comprensión de la incognoscibilidad de las causalidades", KSA X 237-238 y XI 553: bastaría comentar la autoconciencia de este texto para situar su interpretación de Heráclito en su pensamiento. Pero yo seguiré otro camino. 
Yo debería hablar ahor, en el Nietzsche adulto, de la justificación estética del devenir y cómo la conceptualiza, para comprobar mi afirmación inicial de que sería una proyección nueva de una misma estructura de fondo. Pero dada la amplitud del tema me voy a limitar a un aspecto más reducido de esa problemática: su categoría central de «mundo».

¿Y sabéis qué es para mí «el mundo»? ¿Puedo mostrároslo en mi espejo? Este mundo: una enormidad de fuerza, sin comienzo, sin fin, una magnitud firme, férrea de fuerza, que no se vuelve más pequeña, ni más grande, que no se consume, sino que solo se transforma, en cuanto todo invariablemente grande, un patrimonio sin desgastes ni deudas, pero igualmente sin crecimiento, sin ingresos, rodeado por «nada» como por su límite, que nada pierde, nada derrocha, para nada es ilimitadamente extendido, sino colocado, como determinada fuerza, en un determinado espacio, y no en un espacio que estuviera de alguna manera "vacío", más bien, en cuanto fuerza, por doquier, en cuanto juego de fuerzas y ondas de fuerza uno y plural al tiempo, acumulándose aquí y, al tiempo, disminuyendo allí, un mar de fuerzas en sí mismas tempestuosas y crecidas, transformándose eternamente, retirándose eternamente, con ingentes años de retorno, con una crecida y reflujo de sus formaciones, pujando desde las más simples hasta las más complejas, desde lo más tranquilo, fijo, frío, hasta lo más ardiente, salvaje, autocontradictorio, y luego, otra vez, regresando desde la plenitud hasta lo sencillo, desde el juego de las contradicciones hasta el placer de la armonía, autoafirmándose aún en esta igualdad de sus caminos y años, bendiciéndose a sí mismo como lo que tiene que volver eternamente, como un devenir que no conoce ninguna saturación, ningún exceso, ningún cansancio: este es mi mundo dionisíaco de la autocreación eterna, de la autodestrucción eterna, este mundo secreto de las dobles voluptuosidades, este mi Más allá del bien y del mal, sin meta, a menos que haya una meta en la felicidad del círculo, sin voluntad, a menos que un anillo tenga una buena voluntad para sí mismo - ¿queréis un nombre para este mundo? ¿Una solución para todos sus enigmas? ¿Una luz también para vosotros, los más ocultos, los más fuertes, los menos atemorizados, los más nocherniegos? iEste mundo es la voluntad de poder - y nada más! iY también vosotros mismos sois esta voluntad de poder - y nada más!?.

Es este uno de los textos más emblemáticos y brillantes del último Nietzsche y, según él, sería el núcleo de lo que consideraba su mejor obra, la obra de su vida, La voluntad de poder. Dada la autoconciencia nietzscheana sobre su propio pensar, su relevancia es máxima para mi propósito: si logro demostrar que se trata de una nueva proyección de una estructura profunda, habría hecho más verosímil mi tesis.

«Fuerza» es la categoría determinante del mundo: el mundo es fuerza, es decir, energía, tensión. El universo es visto no como una cosa, ni como un lugar, sino como dinamismo puro. Fuerza ilimitada, expresada en conceptos temporales («sin comienzo ni fin») y oposicionales (no está rodeada por nada, ni siquiera por el vacío); consiguientemente, ni recibe su poder de algo que no sea ella ni debe darlo a nadie que no sea ella (ni deudas ni ingresos), es firme; y de magnitud: es tanta la fuerza, que no se desgasta.

Esta fuerza es intrínsecamente contradictoria, porque es una lucha, camina desde lo simple a lo complejo y viceversa, desde la armonía a la disarmonía y viceversa. La ilimitación de esa fuerza no se mide, por tanto, ni por comparación

\section{Cf. KSA XI 610-611.}


a fuerza alguna que no sea ella (porque no la hay), ni consiste en una plenitud a modo de algo logrado, porque su vaivén incesante, su lucha interna impiden esta asociación de la plenitud con el logro y el reposo.

Esta condición es el devenir, en que nada permanece, solo la transformación es la regla: es un devenir de transformación, no de continuación en una misma línea: si fuese una sola línea o en la misma dirección, estaríamos en una teleología y finalismo, idea absolutamente ajena y enemiga de la mentalidad de Nietzsche ${ }^{8}$. Este devenir en que la transformación ni aumenta ni disminuye la realidad que se transforma, que ocurre sin saturación ni exceso, que no se desgasta ni se cansa, ese tipo de devenir es precisamente el ciclo, el flujo y reflujo. Se podría intentar representarlo al modo de una circunferencia, donde después de un tiempo y un periodo, se recomienza otra vez el vaivén. Pero Nietzsche nos previene: ni tiene comienzo ni fin y, por tanto, en ningún lugar o momento podríamos encontrar un apoyo para período alguno; se nos dice que es eterno ese ciclo y, por tanto, esa eternidad no consiste en una repetición ilimitada de periodos duraderos, sino que el presunto ciclo carece de temporalidad alguna; y, puesto que es ilimitado en su fuerza, la infinitud no puede ser reducida a una figura finita.

En realidad, con el uso de estos conceptos Nietzsche está intentando destrozarlos: recurre a nociones temporales para eliminar la temporalidad del mundo, a nociones espaciales para romper todas sus conexiones con una posible localización espacial (continente / contenido). Este uso por parte de Nietzsche de categorías que se destruyen a sí mismas, es decir, con un significado para negar su significado manifiesto en el lenguaje ordinario es perfectamente coherente con la mentalidad y las ideas de Nietzsche: recuerdo solo su crítica al lenguaje como fenómeno cosificador ${ }^{9}$. Nietzsche quiere utilizar el lenguaje para, destrozándolo, meterse sin intermediarios en la realidad, para verla u olerla, como le gustaba decir a él ${ }^{10}$.

Este devenir no debe pagar por nada (no tiene deudas ni ingresos), no es una maldición de una realidad que no permitiera a las cosas estabilizarse o que estuviera ella misma inconclusa, sino que es la autoafirmación de sí misma en su propia realidad, gozándose de ella misma: es una autobendición. El devenir es una bendición, no es motivo de lamento. Frente a la concepción cristiana, según la cual el mundo debe ser rescatado de sí mismo y que tiene como núcleo de su mitología un redentor ${ }^{11}$.

8. Cf. KSA XIII 375; cf. L. E. de Santiago Guervós, Arte y poder. Aproximación a la estética de Nietzsche, Madrid: Trotta, 2004, pp. 624-625.

9. Cf. WL en KSA I 873-890; y C. Crawford, The Begining of Nietzsche's Theory of Language, Berlin: De Gruyter, 1988, sobre las fuentes; para un estudio más matizado sobre las dimensiones críticas, simbólicas, prágmáticas y metafísicas del lenguaje, cf. L. E. de Santiago Guervós, op. cit., pp. 349-467.

10. En esto procede como la mística de todas las épocas y tendencias, que ha recurrido a la contradicción para decir lo impronunciable: y no creo que descubra nada nuevo cuando digo que Nietzsche tiene un parentesco innegable con los místicos: la visión repentina de Zaratustra, en que conocimiento y experiencia se dan la mano en un momento de lucidez transformadora; y su experiecia extática en Sils-Maria, el 14 de agosto de 1881, cf. KSB VI 112, carta 136; sobre el carácter extático de esta experiencia, cf. P. Klossowski, Nietzsche y el círculo vicioso, trad. de I. Herrera, Madrid: Arena Libros, 2004, pp. 83-93.

11. Recuerdo que esta misma idea aparece en Buda, pero sin salvador, en quien Nietzsche estuvo interesado incluso en época muy tardía, cf. AC $\$ \mathbb{\$} 20-23$. 
A esta concepción del devenir Nietzsche le da un nuevo nombre: «la voluntad de poder». No se trata de añadir un concepto nuevo o una dimensión nueva al mundo: es otro nombre nuevo; la descripción que ha hecho del mundo como devenir es la articulación conceptual de la voluntad de poder. Pero si no es un concepto nuevo, sí es una expresión nueva, y en un escritor como Nietzsche, tan consciente del lenguaje y de sus funciones, a quien las palabras se le convierten en chispas creativas, lo menos que podemos hacer es preguntarnos por qué este nuevo término.

Esta expresión la toma, sin duda, de Schopenhauer, que había hablado de la «voluntad de vivir» ${ }^{12}$. Nietzsche interpreta esta idea como «instinto de supervivencia» y reduce este instinto, contra Schopenhauer, a «buscar el placer y evitar el displacer».

Pero a esta concepción opone Nietzsche que este instinto no puede ser lo primero, porque «presupone la existencia y esta, a su vez, el intelecto». Nietzsche no se limita a esta crítica: lo sintomático es que determina esta voluntad con términos como «intensidad» (Stärke), "poder» (Macht). Y termina rechazando la equiparación del hombre con el animal, error en que, según él, habría incurrido Schopenhauer: los animales sí se rigen por este instinto de supervivencia ${ }^{13}$. En este texto de crítica a Schopenhauer aparecen nociones muy queridas para Nietzsche y, además, formando el mismo tipo de constelación que será constante en él: poder, fuerza, vida, voluntad, finalidad de la vida. Pero aún no ha encontrado ni la expresión «voluntad de poder» ni, mucho menos, su alcance metafísico. Para conseguirlo deberá dar los siguientes pasos:

1. descubrir que en la vida no solo hay un principio de conservación, sino, sobre todo, de intensificación: lo logrará cuando advierta que la vida que no crece, decrece;

2. puesto que la inteligencia y la existencia están presupuestas en la vida, deberá

3. unir estas tres nociones y concebir la vida como inteligencia tensional, es decir, como lucidez;

4. de estos dos presupuestos se sigue que «querer la vida por sí misma» es querer la lucidez en cuanto tal; pero no como opuesta al sentimiento o a objeto alguno, porque esa lucidez es la totalidad del ser vivo;

5. como lo que mantiene tensa la vida, como lo que la hace crecer es el poder (Macht), el verdadero afán de la vida, su finalidad, será querer aquello que la hace perdurar y querer: el poder; y como el querer es voluntad, ya tenemos la constelación, «voluntad de poder»;

6. por la percepción de que es la voluntad la que forja las cosas, no meramente las transforma, y, por tanto, no es la inteligencia, surgirá inevitablemente la desconfianza ante la verdad: es el perspectivismo y el interpretacionismo generalizados. Aquello de donde surge todo es el poder: identificarse con él (eso es la voluntad) es el núcleo de la actitud humana, es lo que caracteriza al hombre, no el instinto de conservación, que no nos distingue de ningún animal ni de ningún ser vivo. Guiándose, pues, por Schopenhauer, hemos desembocado en una

12. Cf. A. Schopenhauer, El mundo como voluntad y representación, ed. de R. R. Aramayo, Barcelona: Círculo de Lectores, 2003, vol. I, libro IV, pp. 363-561.

13. Cf. KSA VIII 406-408, 1877. 
concepción bien diferente; con todo ello la lucidez en cuanto ejercicio de la mera inteligencia ha quedado desplazada a un plano secundario.

Pero con todo esto aún seguiríamos en una concepción antropológica de la voluntad de poder, falta dar el salto a su dimensión metafísica:

7. por la ruptura de las dualidades: apariencia / realidad, duradero / transitorio, hombre / mundo, hecho / interpretación, todo / parte, cuerpo / alma, inteligencia / impulso, cosa / lenguaje, exterior / interior...

Nietzsche recoge velas en este texto ditirámbico mostrando la conexión de estas ideas con algunos de sus conceptos más queridos: lo dionisíaco, por lo que tiene de autodestrucción y autoconstrucción eternas; y el más allá del bien y del mal, por lo que tiene de autonomía que a nada ni a nadie da cuenta de su acción. El que Nietzsche recuerde sus otras concepciones pone de manifiesto esta conciencia de variación desde unas estructuras profundas, aunque demostrar esta afirmación nos llevaría también lejos de este trabajo.

En cuanto se compara este fragmento con su interpretación de Heráclito no resulta difícil descubrir el parentesco: el núcleo de la realidad es un devenir bendecido, no maldito, transido de contradicciones inherentes que son las que le dan el dinamismo, en ciclos. Incluso algunos términos son idénticos: flujo y reflujo, lucha, contradicción / armonía, devenir eterno, transformación, destrucción / construcción, saturación. Reaparece, por tanto, esta obsesión nietzscheana por la salvación del devenir tanto en su interpretación de Heráclito como en su conceptualización del mundo.

Pero las obras de superficie jamás son idénticas: serían la misma obra. Cuando un autor da formas diversas a esas estructuras profundas, si bien las obras de superficie manifiestan y plasman esas estructuras profundas, cada plasmación aporta algo; es más, la forma impone su ley y transforma la idea. Probablemente todo el mundo estará de acuerdo en conceder que dos obras distintas aportan y significan algo diferente. Pero casi siempre se suele pensar que la obra posterior matiza la anterior, si es que no la niega, y, por tanto, se suele considerar a la primera obra como primeriza, un primer ensayo o esbozo. Esto es un error: si cada obra es la plasmación de esta estructura de profundidad y si cada obra de superficie es diferente a la otra, el significado de cada obra, la primera y la última, es independiente y además complementario con respecto a la otra. Por eso, es conveniente estudiar lo que cada una de ellas aporta a la otra. Así procederé yo en el caso de la interpretación de Heráclito y este fragmento sobre el mundo.

Lo que el fragmento aporta a la interpretación de Heráclito y aquello en que la complementa es la eliminación del lenguaje cosmológico («elementos», «fuego»): se queda con los rasgos más generales, que valen para cualquier tipo de realidad: contradicciones, ilimitación, eternidad. De ese modo el residuo del lenguaje de su tiempo (en especial, de Kant y de Schopenhauer), que aún era tan claro en la interpretación de Heráclito, desaparece y la reflexión nietzscheana adquiere un torso estrictamente metafísico.

Sustituye «acción» por «fuerza». Con ello consigue varias cosas al mismo tiempo: desantropomorfiza el concepto (acción se aplica a la vida humana) y generaliza su contenido, puesto que fuerza es un concepto general, ni siquiera físico. Permite también establecer las bases para una comparación, puesto que 
la fuerza tiene siempre una intensidad y un potencial diferencial. El estilo no es narrativo, sino expositivo: con ello Nietzsche desplaza el centro de gravedad desde el filósofo a la realidad: el sujeto no es ahora el filósofo que dice cómo es la realidad, sino la realidad misma en movimiento y en autotransformación; y, por si fuera poco, el filósofo cambia también de posición en el texto: deja de ser un oráculo, para convertirse en momento de esa fuerza en baile permanente y bendita; la realidad habla, el lenguaje calla: este es el modo peculiar que tiene Nietzsche de desarticular el lenguaje, además de la contradicción interna que crea dentro de él. Convierte así la realidad en su propia embajadora, ella es su propio oráculo; de ahí el tono ditirámbico del fragmento.

¿Qué aporta la interpretación de Heráclito al fragmento? Que esta transformación permanente por contrarios en el devenir no es una arbitrariedad, sino un proceso, regido por leyes y necesario. Además, que este proceso es «justo»: como lo designará también de proceso estético y no moral, Nietzsche pretende unificar la visión estética (juego) con la visión moral (ley, justicia), utilizando una terminología doble, procedente de cada uno de estos ámbitos. La designación de la categoría de juego al mundo del devenir refuerza esta dimensión y conceptualización estética y moral del devenir. Y, finalmente, la interpretación de Heráclito tiene forma de relato y, según las propias ideas de Nietzsche, interpretar consiste en poner de relieve la conexión de unas ideas con la vida de un personaje para descubrir una personalidad, en los casos eminentes una gran personalidad: no se trata de fabricar personajes históricos o sacarlos del olvido (algo que también Nietzsche consiguió, a pesar de que hoy los presocráticos figuren como la calderilla de todo conocedor filosófico), sino de hacer ver en qué medida la filosofía es vida, no mero conocimiento; de ahí que Nietzsche haga referencia una y otra vez a la actitud del filósofo frente a su saber y a sus contemporáneos, fijándose incluso en su modo de vestir y de peinar: el desdén del filósofo, su destacarse frente a los demás, la contemplación de la naturaleza como forma de vida.

Insisto en el carácter estrictamente metafísico de este concepto de mundo: no se trata ni de los significados que nosotros asignamos a la realidad ni del modo como el hombre actúa; se trata de que la realidad misma («mundo») tiene esa condición de devenir, de fuerza contradictoria. Subrayo esta condición metafísica, porque cuando se menciona esta dimensión del pensamiento de Nietzsche o es para negarla o para olvidarla inmediatamente después de mencionarla ${ }^{14}$.

14. Sin embargo, hay conciencia de esta doble problemática desde muy pronto, centrada, sobre todo, en la interpretación del «eterno retorno", cf. K. Jaspers, Nietzsche. Einführung in das Verständnis seines Philosophierens, Berlin: De Gruyter, ${ }_{3} 1950$, p. 359, que distingue entre «hipótesis fisicocósmica» / «contenido de la creencia»; ibid., p. 136, que distingue entre el «cosmológico» / «antropológico» («ético»). Heidegger ha sido el que mayor empuje ha dado a la interpretación metafísica en sus cursos de finales de los treinta y comienzos de los cuarenta: Nietzsche, trad. de J. L. Vermal, Barcelona: Destino, 2005, en especial, pp. 274-288. Solo tienen una visión antropológica y ética de la voluntad de poder y del eterno retorno, D. Sánchez Meca, El nihilismo. Perspectivas sobre la historia espiritual de Europa, Madrid: Síntesis, 2004, pp. 128-140, y Nietzsche. La experiencia dionisíaca del mundo, Madrid: Tecnos, 2005, pp. 119-130. Para una breve pero sustanciosa defensa de una ontología en Nietzsche, cf. J. I. Galparsoro, «Nietzsche y el problema ontológico categorial. El devenir como continuidad", en V. Gómez Pin (coord.), Categorías e inteligibilidad global. El proyecto ontológico a través de la reflexión contemporánea. Actas del Primer Congreso Internacional de Ontología, Barcelona: Universitat Autònoma de Barcelona, 1994, pp. 209-215; y sumamente lúcido también J. Richardson, Nietzsche's System, New York-Oxford: Oxford UP, 1996, pp. 16-141. 
Con todo ello, la realidad pasa a ser sujeto, he dicho. Quizá desde aquí podamos entender el cambio más evidente de lenguaje entre la interpretación de Heráclito y el fragmento póstumo: la voluntad de poder. Esta expresión parece contradecir cualquier interpretación metafísica, puesto que supone una gigantesca antropomorfización de la concepción de la realidad: todo lo que hay pasa a ser designado con dos términos del mundo humano, voluntad y poder. No me extraña que los intérpretes hayan sido inducidos a una interpretación antropomórfica. Nosotros debemos luchar contra ella al tiempo que debemos preguntarnos por qué emplea este término claramente antropomórfico. Y hay que recordar que Nietzsche está hablando del «mundo», es decir, de la realidad del devenir, del devenir en cuanto realidad, que no hay otra. Y que nos afirma que esa es no una desginación provisional o para algún aspecto de lo real o del mundo, por muy importante que fuera, sino la designación esencial del mundo. El mundo queda, por tanto, antropomorfizado (a pesar de esa dimensión metafísica, porque la elección de las palabras expresan las tendencias de las concepciones, en especial, en un pensador tan clarividente acerca del poder (en general, negativo) de las palabras, y de un pensador que llegó a decir que «no hay cosas, solo interpretaciones». Si queremos tomar a Nietzsche en serio, lo primero es advertir el tipo de lenguaje que utiliza. $\mathrm{Y}$ «voluntad de poder» es una expresión antropomórfica.

Con ello Nietzsche logra una moralización completa de su concepción de la realidad. Mientras que en La filosofía en la época trágica de los griegos contraponía la justificación moral a la justificación estética del mundo (Anaximandro / Heráclito) esta nueva expresión asume las dos eliminando su oposición. Se podría pensar que Nietzsche se ha pasado al bando de la justificación moral del mundo: pero eso no lo hizo Nietzsche jamás. Y como su descripción del «mundo» incluye aspectos relevantes de la inocencia del devenir, es decir, de la justificación estética del mundo, Nietzsche trata de eliminar dualismos. ¿Por qué? No por interés conciliatorio alguno: la armonía no es su fuerte. Sino, a mi entender, por coherencia con su propia concepción del devenir como contradicción permanente, que incluye lo uno y lo otro: la voluntad de poder es una manera de designar el mundo en cuanto incluye la contradicción de la justificación ética y la justificación estética como momentos intrínsecos suyos.

Con esta antropomorfización Nietzsche elimina también la oposición entre hombre y realidad: pudiera parecer que no es así, que Nietzsche asimila la realidad al hombre. Pero el hombre queda absorbido en este mundo como uno de sus aspectos, de sus dimensiones, de sus elementos o de sus contradicciones. La compenetración de mundo y hombre es total. Pero, que quede bien claro, no como dos cosas diferentes y bien avenidas, sino por la eliminación de la dualidad misma.

Por ello, la «fuerza» adquiere la forma de «poder» (Macht). Entre las numerosas orientaciones y dimensiones que se pueden describir en la voluntad, una, entre otras, es el poder. Elegir el bien frente al mal (o a la inversa), inventar lo mejor (o lo peor), establecer relaciones sociales o aislarse, amar u odiar, dominar. El poder no es la capacidad de controlar las cosas, porque eso supone una actuación desde el exterior hacia ellas. Macht es ese momento en la realidad en virtud del cual esa realidad no es mera estancia o mera inercia, sino intensidad: si no fuera porque Nietzsche no utliza una terminología física y porque piensa en términos de contradicciones, podríamos decir que Macht recoge lo que el concepto de «campo» tiene de tensional. 
El otro término, el propiamente antropomórfico es el de «voluntad». Voluntad se opone a inteligencia y a memoria en la teoría clásica de las facultades humanas, oposición que no hay que descartar en Nietzsche, puesto que procede de ese ámbito, tanto por lo que tiene de formación en su propia familia y la teología protestante como por lo que tiene de conocimiento de Kant, en el que se ha educado y al que cita una y otra vez en La filosofía en el ápoca trágica de los griegos. La voluntad es la facultad de la toma de decisiones. Frente a las filosofías de la inteligencia (practicamente todas), Nietzsche prefiere la voluntad. ¿Por qué? Porque la inteligencia está contaminada por la conceptualización y, por tanto, por la exclusión del sujeto: el hombre quedaría encerrado en esa cáscara que lo envuelve como una maraña:

Lo que ahora llamamos «el mundo» es el resultado de un montón de errores que surgieron poco a poco en la evolución total de los seres orgánicos, se entrelazaron mutuamente y ahora se heredan como tesoro acumulado de todo lo pasado ${ }^{15}$.

En este texto «mundo» es una representación (Vorstellung), no tiene un sentido metafísico: es el Nietzsche debelador. Si lo comparamos con el texto antes aducido y que estoy comentando, comprobamos una vez más la táctica mental de Nietzsche: utilizar el lenguaje tradicional de la metafísica para destrozarlo desde dentro.

Y no hay que olvidar, finalmente, en el uso de «voluntad» a su antiguo mentor, Schopenhauer, que opuso tajantemente la voluntad a la representación, dando prioridad a la voluntad como el modo de introducirsse en el mundo.

Cuando Nietzsche propone la voluntad como designación de lo real, subraya el momento de autonomía del cosmos: es una autoafirmación del mundo en sí mismo, nada que ver con Zeus. Cualquier residuo de una presunta dependencia, aun metafórica o mitológica, queda eliminado. El mundo solo se vive desde sí.

¿A qué categoría sustituye «voluntad de poder»? A «juego de Zeus». El juego desaparece en esta terminología nueva. Con ello se subraya la originariedad del mundo, mientras que el término «juego» implicaba un cierto momento de arbitrariedad. Sin embargo, ambos aspectos, el de arbitrariedad y el de originariedad, están recogidos tanto en la interpretación de Heráclito como en este fragmento sobre el mundo. En Heráclito, porque no hay poder superior a Zeus, porque él no da cuenta a nadie de su actuación, porque el fuego se transforma de acuerdo a leyes que nadie conoce ni, sobre todo, controla: el fuego es autónomo respecto a los otros elementos y el universo en su devenir actúa con la decisión imprevisible de un artista: es originario y arbitrario. En el fragmento, la voluntad genera contradicciones sin cuento, no regidas por ley alguna que sea exterior a ella misma.

El cambio de lenguaje, pues, no supone cambio de concepción: la misma estructura profunda toma dos formas de superficie diferentes, la narrativa (juego), la sistemática (voluntad de poder).

Este cambio de lenguaje en que la antropomorfización voluntariosa asume el mando coincide con el apartamiento progresivo de Nietzsche respecto a Schopenhauer. Esto no deja de tener su importancia. Para comprenderlo, lo tenemos que poner en conexión con su primigenio rechazo a la justificación moral del mundo: curiosamente ahora asume la justificación del mundo una forma moral. Ya he indicado antes que con esta expresión Nietzsche está dando una nueva noción de mun-

15. Cf. KSA VIII 447-448, 1877. 
do moral. Y conviene subrayarlo: Nietzsche no se reconcilia con la moral, como si hubiera dado un paso atrás y se desdijera de sus críticas feroces a la moral, de las cuales nunca se desdijo, ni en sus escritos publicados ni en sus manuscritos.

Lo que ha ocurrido es que Nietzsche descubre en la voluntad el punto común desde el que surgen los dos tipos de actuación, el moral y el artístico: ambos suponen la creación libre. Y no hay creación libre sin decisión, es decir, sin voluntad. Pero así como para nosotros nos resulta muy fácil comprender ya que la actividad artística no consiste en reproducir modelos ajenos, sino en "crear» inventivamente -idea que se la debemos al arte y a la estética del siglo xx-, en moral todavía rigen dos ideas entrelazadas: primera, que la moral es un conjunto de preceptos o comportamientos universales y comunes (aunque a veces no sepamos exactamente cuáles son los válidos); y, segunda, y precisamente por eso, lo moral consistiría en elegir entre esos preceptos, más básicamente, entre cumplirlos o incumplirlos: el momento moral sería el de la elección.

Pero ambos principios morales son opuestos por completo a la moral de Nietzsche. Porque él singulariza la moral: la moral nace desde uno mismo, los principios morales universales son plebeyos. Y, en segundo lugar, porque cada cual debe crear su propia moral, para lo cual hace falta ser inventivo, y no todo el mundo tiene esa capacidad: el momento moral no está en la elección entre el bien y el mal, sino en la invención de formas de vida.

Concebida así la moral, es fácil ven en qué coinciden la actividad moral y la artística: ambas son creativas, porque ambas son originarias y ambas nacen del sujeto. Y el núcleo de esa capacidad es el querer. Como para producir una obra de arte hay que luchar contra la resistencia de los materiales, contra las tradiciones, contra el lenguaje que en vez de facilitar la tarea la dificulta, no basta querer, hace falta también poder. Y como en la vida moral el destacado solo logra vivir su vida desprendiéndose del afán de apoderamiento de los demás, de su resentimiento, la vida moral creativa no resulta nada fácil: también en la vida moral no basta solo desear la libertad, sino que hay que tener la capacidad de conseguirla. $\mathrm{Y}$ a este poder en ambos terrenos Nietzsche llama con acierto Macht. Sus héroes son simpre luchadores contra corriente: en Más allá del bien y del mal, en La genealogía de la moral, en el Zaratustra. En conjunto, voluntad de poder. Se trata de un nuevo efecto de espejos: porque voluntad de poder no desplaza al juego como una categoría nueva, sino que nos describe la esencia del juego: originariedad, autonomía; creatividad, en suma: el juego es voluntad de poder.

Si nos retrotraemos ahora a la proyección «mundanal» (cósmica) de este concepto, descubrimos su sentido: el universo busca la autoafirmación creativa y tiene, además, el poder de conseguirla. No extraña, entonces, que Nietzsche bendiga este mundo, tal como es (devenir contradictorio), porque es el prototipo de cualquier otra actuación, es el humus de cualquier otra actividad. Pero no caigamos ahora en la trampa de creer que el hombre actúa como actúa la naturaleza: sería una nueva teoría de la imitación en la que Nietzsche nunca cayó ${ }^{16}$. Pero justificar esta afirmación nos sacaría de este artículo.

16. Para la voluntad de poder como arte, cf. M. Heidegger, op. cit., pp. 17-205; y también L. E. de Santiago Guervós, op. cit., pp. 473-645, con una cuidadosa distinción entre el alcance metafísico del concepto de voluntad de poder y su utilización como categoría para esclarecer el arte y la estética. 